\title{
RESENHA DE “MORFOLOGIA: ESTUDOS LEXICAIS EM PERSPECTIVA SINCRÔNICA", DE CLAUDIO CEZAR HENRIQUES
}

\author{
José Mario BOTELHO \\ Universidade do Estado do Rio de Janeiro e Academia Brasileira de Filologia \\ botelho mario@hotmail.com
}

O Professor Doutor Claudio Cezar Henriques é catedrático da Universidade do Estado do Rio de Janeiro (UERJ), onde é Professor Titular de Língua Portuguesa, e Membro Efetivo da Academia Brasileira de Filologia (ABRAFIL).

Esta obra "Morfologia: Estudos lexicais em perspectiva sincrônica" é um dos 4 (quatro) livros que o Prof. Henriques publicou pela Editora Elsevier na Coleção "Português na Prática". E, como sugere o título da referida coleção e a orelha da capa, este livro objetiva dar conta do conteúdo das aulas e de cursos de Português, no que se refere à morfologia, sob uma visão moderna e produtiva.

Segundo o editor, neste livro, os estudos morfológicos do português são apresentados em seus aspectos lexicais e flexionais, com ênfase nas explicações clarividentes dos conceitos básicos necessários à análise e compreensão dos morfemas da língua portuguesa. Também é feita a descrição minuciosa das classes de palavras, dos elementos estruturais da palavra e dos seus processos de formação, como se espera de qualquer estudo de morfologia.

Esta 4⿳亠丷 edição (ampliada e atualizada), publicada em 2014, também pretende expor e interpretar as consequências das alterações ortográficas, promovidas pelo Acordo Ortográfico, de 1990, que está em vigor desde 2009, mas que só foi promulgado em $1^{\circ}$ de janeiro de 2016.

No prefácio, o próprio autor faz alusão à promulgação do Acordo Ortográfico e explica que esta $4^{a}$ edição se faz em função de certas mudanças, implementadas pelo referido Acordo. $\mathrm{O}$ autor enfatiza a regra sobre a proibição do hífen entre os elementos enclíticos "não" e "quase" e a palavra base em formações como: "não agressão" (antes grafada "não-agressão", "quase irmão" (antes grafada "quase-irmão"). Como tal regra incide diretamente sobre 0 
processo de formação de palavras até então denominado "derivação prefixal" ou "prefixação", logo, um aspecto de estudos morfológicos, o autor justifica o seu interesse e anuncia a necessidade de esclarecer essa e outras situações problemáticas em relação à morfologia, causados pela reforma ora proposta pelo tal Acordo.

A obra, que segue os moldes tradicionalistas de análise, é dividida em três partes, a partir das quais os pontos formais da morfologia portuguesa são apresentados, seguidos de esclarecimentos sob a ótica da tradição gramatical, e um Apêndice com questões selecionadas do Exame Nacional de Cursos Letras.

O autor inicia com uma breve apresentação de conceitos teóricos básicos de sincronia, diacronia, sintagma, palavra e morfema, como se indicasse ao leitor o seu posicionamento acerca de uma fundamentação teórica para os fatos morfológicos que serão estudados a seguir.

Na primeira parte (Parte I: conceitos básicos, p. 3-14), Henriques faz uma apresentação sintética acerca do estudo da morfologia, definindo-a com "o estudo das unidades e dos princípios que regem a estrutura interna da palavra, seja pela formação de novas bases lexicais, seja pela sua flexão" (p. 1) e esboça os conceitos de sincronia e diacronia no item 1 ("Sincronia e diacronia").

Apesar da brevíssima explicação desses dois importantes conceitos nesse item 1 (da Parte I), o leitor pode perceber a importância da sua aplicação na análise dos fatos gramaticais. $O$ autor também aproveita a oportunidade e tece uma sintética crítica à postura das nossas gramáticas, que, segundo ele, confunde esses dois aspectos nas suas explicações de certos fatos gramaticais.

No item 2 ("Sintagma, palavra e morfema"), os conceitos tornam-se um pouco mais desenvolvidos. No subitem 2.1 ("Sintagma (e paradigma)"), primeiramente se tem a definição de sintagma, transcrita do dicionário de Bussmann (1996, p. 472). Em seguida, apresenta, sem digressionar a respeito, 
as definições de sintagma, dadas por Saussure (1972, p. 142), Trask (2004, p. 249) e Câmara Jr. (1981), p. 332-3).

Depois, no subitem 2.2 (“Palavra (e vocábulo)"), apresenta as noções de diversos linguistas sobre os termos "palavra" e "vocábulo", demonstrando que a distinção entre os dois conceitos não tem sido, de fato, nítida.

Por fim, Henrique considera totalmente supérflua a possibilidade de se definir como diferença técnica a noção de que "bastaria vincular palavra a radical e concluir que toda palavra é um vocábulo, mas nem todo vocábulo é uma palavra - esta só existe quando existe um morfema lexical” (p. 8). Logo, além de não dar fim à polêmica acerca da distinção entre palavra e vocábulo, o autor a torna ainda mais evasiva.

Finalizando a Parte I, ainda nesse item 2, o autor inicia o subitem 2.3 ("Morfema (e lexema)") com uma evasiva definição de "morfema", feita por Mounin (1993, p. 212), que afirma não serem os morfemas formas desprovidas de sentido.

Em seguida, desenvolve-se um posicionamento crítico contra a tradição gramatical quanto à fragilidade de sua distribuição em classes de palavras daquilo que o autor considera vocábulos formais (como o fez Câmara Jr. em seu Estrutura da língua portuguesa). Lembra que, nas gramáticas tradicionais, não há um tratamento uniforme para a definição das classes de palavras, as quais são determinadas por critérios ora sintáticos, ora semânticos, ora morfológicos, ora por combinações desses critérios (Cf. p. 8).

Depois de digressionar, de forma breve, sobre a classe de palavras, tendo como escopo o "advérbio", assume a proposta de Câmara Jr. e agrupa os vocábulos formais em quatro classes: nome, verbo, pronome e conectivos.

Também se posiciona sobre o morfema e, corroborando a opinião de Silva e Koch (1997, p. 27-8) de que "do ponto de vista pedagógico, parece mais adequado considerar morfema o significante mais usual e sistemático da língua (forma básica) e os demais como variações ou alomorfes". Daí, concluir que "o morfema é todo e qualquer constituinte de um vocábulo, englobando os lexemas (morfemas dotados de significação externa, chamados morfemas 
lexicais) e os gramemas (morfemas dotados de significação interna, chamados de morfemas gramaticais)" (p. 10).

Para fechar a Parte I, Henriques propõe um exercício de 10 (dez) questões, das quais apenas duas são de múltipla escolha, e oferece as respostas.

Na Parte II (“Estrutura dos vocábulos”, p. 15-111), desenvolvem-se 4 (quatro) itens: "morfemas do português", "Padrão dos verbos", "A classe dos nomes" e "Demais classes". Como sugere o título dado pelo autor, serão estudados os elementos estruturais dos vocábulos. Por isso, no item 3 ("Morfemas do português), retoma a noção de morfema por considerá-lo fundamental ao estudo sobre a estruturação dos vocábulos, a qual se dá a partir da combinação de morfemas.

No subitem 3.1 (“Raiz e radical”), o autor observa que o "radical primário (irredutível), numa dada série, pode ser apontado como a raiz - elemento que encerra a significação fundamental” (p. 17) e, corroborando Rocha Lima (1992, p. 167), assume que "não se busca ascender à determinação de raízes, tomase como ponto de partida o radical" (p. 18).

Em 3.2 ("Vogal temática e tema"), ressalta ser imprópria a determinação de vogal temática para os nomes, mas reconhece a função de "viabilizar o radical como vocábulo, para uns nomes, e formar o tema, para outros" (p. 18).

No subitem 3.3 ("Desinências e afixos"), apresenta-se uma longa explanação, na qual Henriques cita diversos autores, observando que alguns fazem referências a "sufixo (ou morfema) flexional, como sinônimo de "desinência". Contudo, ele prefere conservar a nomenclatura tradicional para evitar a subdivisão consequente: "sufixo flexional" e "sufixo derivacional". Depois, comenta sobre as noções conflitantes de "prefixo", e, embora a considere indesejável, não apresenta o seu ponto de vista. Também comenta, de forma sintética, sobre os termos "prefixoides" e "sufixoides", estudados por Sandmann (1996, p. 108 e 114) e, por considerar problemáticas as suas definições, assume preferir não empregar tais nomenclaturas. 
Em 3.4 ("Elementos de ligação"), observa que "os elementos de ligação, vogais e consoantes, eventualmente são citados como infixos, posição teóricodescritiva pouco adotada pelos tratadistas em relação ao português (MONTEIRO, 1998) e afirma que só devem ser considerados infixos os afixos que se intercalam na raiz, mecanismo que não ocorre no português.

Depois de observar as propostas de Macedo (1987, p. 79-84) e de Cunha e Cintra (2010, p. 95) para os elementos de ligação no português, apresenta uma longa relação de tais consoantes e vogais de ligação, ilustrada com uma grande variedade de exemplos, retirados de nossas gramáticas.

Em seguida, comenta as observações de Bechara (2009, p 339) e de Câmara Jr. (2012, p. 150) e tece uma crítica à opinião de Silveira Bueno, a qual deve ser descartada por ser autoritária, segundo Henriques, e por se inconsistente, uma vez que já afirmara anteriormente não existir infixo em português (Cf. p. 29).

Finaliza esse subitem 3.4, asseverando ser a melhor análise "aquela que preserva a coerência descritiva nos estudos da estrutura dos vocábulos formais e que leva em conta a função dos morfemas existentes na língua" (p. 29). Em seguida, apresenta um exercício com 5 (cinco) questões discursivas, seguidas de suas respostas.

Em "Padrões dos verbos" (item 4), seguindo o padrão da GT (Gramática Tradicional), o autor dá o mesmo tratamento tradicional aos verbos. Afirma que o verbo é "uma categoria de vocábulo de marcante multiplicidade flexional, o que acarreta um levantamento de certo modo exaustivo para que seja estabelecido o seu padrão geral" (p. 33); anuncia a fórmula: "(PREF +) RAD (+ SUF ) + VT + (DMT + DNP) (DFN)", que compõe a estrutura das formas verbais; e se limita à exposição do quadro das "desinências" (DNP e DMT) dos paradigmas das três conjugações (1 $1^{a}$ em "-ar", $2^{a}$ em "-er" e $3^{a}$ em "-ir") e dos dois verbos anômalos: "ser" e "ir".

Para fechar esse item 4, propõe um exercício com 10 (dez) questões. 
Em "Classes dos nomes" (item 5), o autor inicia com uma crítica negativa aos estudos feitos por gramáticos e linguistas, que, segundo ele, não passam de "soluções precárias" ou "saídas pela tangente" (Cf. p. 65).

Em seguida, passa a refletir sobre as conceituações das classes que foram feitas ao longo dos estudos tradicionais. Cita Mira Mateus et alii (2003, p. 210); passa muito rapidamente por Câmara Jr. (1970, p. 67-70), Azeredo (2001, p. 6-13) E Basilio (1980, p. 49-50); tece um comentário breve sobre a afirmação, feita por Melo (1976, p. 207-8), de que no português "o acento enfático recai sempre no segundo elemento de um sintagma dual; o bom filho, o velho amigo, amigo velho"; discorda de Cunha quando afirma que "a subdivisão dos nomes portugueses em substantivos e adjetivos obedece a um critério basicamente sintático, funcional” (CUNHA, 2010, p. 260), uma vez que acredita que a base está, de fato, numa "combinação dos aspectos semântico e funcional" (Cf. p. 67). Henriques assume que "substantivos" e "adjetivos" representam "seres", cabendo àqueles nomeá-los e a estes, caracterizá-los (Cf. $67)$.

Em seguida, afirma que, "diferentemente dos verbos, os nomes portugueses (...) apresentam pequena variedade flexional (p. 68). Sobre o fato de a GT apregoar que os nomes "flexionam-se em gênero, número e grau", afirma que "o gênero e o número estão entre os processos flexionais de nossa língua, o que inegavelmente não é o caso do grau, onde existe com nitidez um processo derivacional" (Cf. p. 69). Depois, corroborando a afirmação, feita por Câmara Jr. (1980, p. 72), de que "na flexão há obrigatoriedade e sistematização coerente", conclui que "enquanto a flexão de gênero e número é a mesma entre os substantivos e adjetivos, (em ambos, masculino/feminino e singular/plural) as marcas de grau são diferentes nas duas classes" (Cf. p. 68).

Em 5.1 ("Padrões dos substantivos e adjetivos"), passa a tratar da estrutura desses nomes em suas flexões, adotando a seguinte tradicional fórmula geral: "(PREF +) RAD (+ SUF) + VT (DG) + (DN)".

No subitem 5.1 .1 ("Desinência de gênero e vogal temática”), para reforçar a sua ideia de que a descrição tradicional dos nomes se vale das oposições 
entre os traços morfossintáticos, que os distinguem em masculino/feminino e singular/plural, para a identificação dos morfemas, Henriques se vale da noção que os estudiosos têm das vogais temáticas (VT) nominais primeiramente.

Afirma que os autores divergem em relação à identificação dos elementos terminais "-o" e "-a", visto que há quem prefira considerá-los desinências de gênero (DG), e outros que preferem considerar apenas a marca de feminino como DG e o "-o" como VT. Depois disso, enumera autores que se posicionaram contra a marca desinencial de masculino e os que se posicionaram a favor da tal marca, e assume considerar o “-o", dos nomes, uma marca de masculino e "-a", uma marca de feminino, inclusive nos substantivos. A sua justificativa se fundamenta em ocorrências em diferentes registos de linguagem, segundo o autor, tais como: "ídola"; "sargenta"; "prostituto"; "pássara", "estrelo" e até "Cleópatro" e "dicionária"!! Na busca de um critério coerente para a descrição de tais ocorrências, Henriques lança mão da proposta, feita por Câmara Jr. (1980, p. 88-9), acerca do que aquele autor considerou feminino psicológico em exemplos como: "jarro/jarra, barco/barca", em que "o masculino é uma forma geral não marcada, e o feminino indica uma especialização qualquer" (CÂMARA JR., 1980, p. 88-9).

Em 5.1.3 ("Desinências de número"), Henriques se limita a repetir o que se tem sobre o assunto na nossa literatura, tendo como pano de fundo a noção de alomorfia da desinência de número nos moldes da proposta de Câmara Jr. (1980).

Em "Padrões dos advérbios" (item 5.2), o autor inicia o item, ressaltando haver consenso entre os que se propõem a analisar a estrutura dos vocábulos, no que se refere ao fato de os verbos, os substantivos e os adjetivos receberem descrição, e se mostra admirado pelo fato de o advérbio, que também é uma palavra dotada de significação externa, não ter sido descrito nos estudos morfológicos tradicionais.

Assim sendo, esboça, em seguida, uma descrição dos advérbios sincronicamente primitivos, posto que "os não primitivos já teriam sido descritos no estágio constituinte anterior" (Cf. p. 85). Propõe, pois, a seguinte fórmula 
para os referidos advérbios: "RADICAL + VT -a, -e ou -o" e "RADICAL + VT zero".

Depois, apresenta um quadro com definições para o advérbio, que considera contraditórias, e propõe que o advérbio seja definido como "palavras suplementares modificadoras não qualificativas e não denominativas" (p. 93), que, a seu ver, é melhor que a também evasiva, dada pelas gramáticas e dicionários (a saber: "palavras modificadoras de verbos, adjetivos ou advérbios") (Cf. p. 93).

Para finalizar esse item, propõe um exercício com 20 (vinte) questões e suas respostas.

Em "Demais classes" (item 6), depois de ressaltar que "são categorias lexicais os substantivos, os adjetivos, os verbos e os advérbios" e deslocar as preposições para o grupo de "categorias funcionais", anuncia que vai descrever as classes dos numerais, pronomes, artigos, preposições, conjunções e, inclusive, as interjeições. Contudo, Henriques se limita a repetir o tratamento dado pelas gramáticas às classes.

Para finalizar esse item 6, também propõe um exercício com 5 (cinco) questões, seguidas de suas respostas.

A Parte III ("Processos de formação", p. 113-81), que se desenvolve praticamente na outra metade do número de páginas do livro, Henriques trata dos dois principais processos de formação de palavras: Composição e Derivação e elenca outros casos de formação de palavras.

Ele inicia este item com uma pequena citação de Basilio (1995, p. 15), em que aquela autora critica a postura das gramáticas tradicionais por se limitarem a enumerar processos de formação de palavras e listar exemplos. Henriques reitera a referida citação e acrescenta que "a formação de palavras é tema que requer maiores cuidados por parte dos estudiosos" (Cf. p. 113).

Observa que a Nomenclatura Gramatical Brasileira (NGB) se limita a fazer referências apenas aos temas "derivação, composição e hibridismo", o que é bem conveniente, já que a referida NGB tem a finalidade de tão simplesmente orientar os estudos gramaticais e não constitui mesmo um estudo em si. E 
afirma, ainda, que "o hibridismo deve ser visto como um termo complementa no quadro classificatório dos processos de composição ou de derivação, igualmente restrito aos morfemas de base sincrônica" (Cf. p. 114).

Em "Composição e derivação" (item 7), apresenta, de forma sintética e à semelhança das gramáticas, a composição (subitem 7.1), que pode ser por justaposição ou aglutinação.

Em 7.2 ("Derivação"), muitíssimo rapidamente o autor apresenta exemplos de prefixação e de sufixação e passa a tratar dos casos em que a formação de uma dada palavra se dá com o acréscimo de ambos os afixos (a saber, prefixo e sufixo) simultaneamente.

Como há casos em que tal processo se caracteriza como uma parassíntese, sobre a qual a NGB não fez alusão, e por achar o autor que tal fato constitui uma falha da NGB, que, na sua opinião, deveria ser corrigida (Cf. p. 118), desenvolve tal tema até o final desse item, quando o fecha com um exercício de 10 (dez) questões, seguidas de suas respostas.

Em "Processos especiais" (item 8), o autor trata dos seguintes processos: regressão, abreviação, reduplicação e conversão (ou derivação imprópria), que considera um pseudoprocesso.

Como o tratamento dado é o mesmo dado pelas nossas gramáticas, salvo o comentário acerca do que denominou um pseudoprocesso, já que "qualquer palavra pode ser substantivada e qualquer substantivo pode ser adjetivado" (Cf. p. 134) - como se só ocorressem esses casos de conversão -, Henriques fecha o item 8 com a sua proposta de exercício com 10 (dez) questões e suas respostas.

Em "Outros casos" (item 9), que é o último dessa terceira e última parte do livro, Henriques trata dos seguintes processos: siglas e abreviaturas, neologismos e estrangeirismos.

Em 9.1 ("Siglas e abreviaturas"), destaca-se apenas a observação acerca de, em "alguns casos, a sigla poder coincidir com a aglutinação de partes menores dos vocábulos" (Cf. 142). 
Em 9.2 ("Neologismos"), o autor, dividindo os neologismos em quatro tipos distintos: lexicais (ou formais), estrangeirismos, semânticos e epônimos, ilustra com uma variedade de exemplos contextuais.

Em 9.2.1 ("Tipologia neológica”), entre os neologismos lexicais, Henriques observa que há os que são criados, sem nenhuma lógica lingüística aparente, os quais Alves (1990) denominou "neologismo fonológico", e os que, na maioria dos casos, são criados a partir de outros já existentes na língua.

O neologismo por estrangeirismo o autor o considera um caso especial de neologismo lexical (ou formal) e, depois de se alongar bastante sobre a sua prática, afirma que "os empréstimos lingüísticos são frutos do contato entre os povos e podem resultar na criação de neologismos semânticos e lexicais" (Cf. p. 149). E se alonga, também, sobre os neologismos semânticos e lexicais e os epônimos (permanentes, restritos, efêmeros e ambíguos).

Em 9.3 (“Combinação de processos (unidades complexas)"), o autor tece um brevíssimo comentário sobre os dois casos: acumulação de um mesmo processo e acumulação de processos diferentes.

Em 9.4 ("Cruzamento morfológico e fracionamento vocabular"), o autor apresenta casos de cruzamentos morfológicos e fracionamentos vocabulares e fecha esse item 9 com o seu exercício de 15 (quinze) questões, seguidas dos suas respostas.

Por fim, Henriques apresenta, como Apêndice, uma seleção de questões de morfologia, extraídas dos Exames de Letras dos anos de 1998, 199, 2000, 2001, 2002, 2003, 2005, 2008 e 2011, os quais podem ser úteis, como observa o próprio autor, para uma reflexão sobre a formação dos novos professores de língua portuguesa do país, pelo menos em relação aos estudos de morfologia.

Ao finalizar esta resenha (que considero muito mais um resumo da obra em questão), espero ter deixado claro que o Professor Doutor Claudio Cezar Henriques oferece ao público leitor, que se espera interessado nos estudos morfológicos da língua portuguesa, um manual de morfologia propriamente dito. Nele, encontramos, grosso modo, o que se tem sobre os aspectos de morfologia portuguesa na nossa literatura de natureza gramatical, logo, 
tradicional, já que as noções e conceituações de tais aspectos constituem o escopo da obra resenhada.

Encontramos, também, algumas considerações críticas, em alguns casos de ordem teórico-linguística, contudo o presente trabalho não constitui o que se poderia denominar "um estudo teórico-científico", que pudesse integrar o rol de obras fundamentais de estudiosos especializados e críticos e pesquisadores do tema.

Trata-se, pois, de um livro didático que pode ser útil àqueles que se interessam pelo estudo de morfologia portuguesa, mormente, do português do Brasil.

Convém lembrar, entretanto, que o trabalho em questão tem como base o seu trabalho de Dissertação de Mestrado, que foi defendido em 1981, como o próprio autor enfatiza no Prefácio de sua primeira edição. 